\title{
APPLICATION OF FWD DATA IN DEVELOPING DYNAMIC MODULUS MASTER CURVES OF IN-SERVICE ASPHALT LAYERS
}

\author{
Nader SOLATIFAR ${ }^{\mathrm{a}}$, Amir KAVUSSI ${ }^{\mathrm{a}}$, Mojtaba ABBASGHORBANI ${ }^{\mathrm{b}}$, \\ Henrikas SIVILEVIČIUS ${ }^{c}$ \\ ${ }^{a}$ Faculty of Civil and Environmental Engineering, Tarbiat Modares University, Tehran, Iran \\ ${ }^{b}$ Consultant Engineering Office, Technical and Soil Mechanics Laboratory, Tehran, Iran \\ ${ }^{c}$ Department of Transport Technological Equipment, Vilnius Gediminas Technical University, Vilnius, Lithuania
}

Received 08 Sep 2016; accepted 21 Dec 2016

\begin{abstract}
This paper presents a simple method to determine dynamic modulus master curve of asphalt layers by conducting Falling Weight Deflectometer (FWD) for use in mechanistic-empirical rehabilitation. Ten new and rehabilitated in-service asphalt pavements with different physical characteristics were selected in Khuzestan and Kerman provinces in south of Iran. FWD testing was conducted on these pavements and core samples were taken. Witczak prediction model was used to predict dynamic modulus master curves from mix volumetric properties as well as the bitumen viscosity characteristics. Adjustments were made using FWD results and the in-situ dynamic modulus master curves were obtained. In order to evaluate the efficiency of the proposed method, the results were compared with those obtained by using the developed procedure of the state-of-the-practice, Mechanistic-Empirical Pavement Design Guide (MEPDG). Results showed the proposed method has several advantages over MEPDG including: (1) simplicity in directly constructing in-situ dynamic modulus master curve; (2) developing in-situ master curve in the same trend with the main predicted one; (3) covering the large differences between in-situ and predicted master curve in high frequencies; and (4) the value obtained for the in-situ dynamic modulus is the same as the value measured by the FWD for a corresponding frequency.

Keywords: dynamic modulus, Witczak prediction model, Falling Weight Deflectometer (FWD), Mechanistic-Empirical Pavement Design Guide (MEPDG), in-service pavements.
\end{abstract}

\section{Introduction}

Structural evaluation of pavements has a major role in any Pavement Management System (PMS) due to the high costs of pavement rehabilitation activities. This evaluation is necessary both for estimating remaining life of inservice pavements and also for overlay design purposes. Usually nondestructive testing (NDT) is used to evaluate in-service pavements due to the short time required and low expenses. On the other hand, the Mechanistic-Empirical Pavement Design Guide (MEPDG) (ARA 2004) uses dynamic modulus $\left(\left|E^{*}\right|\right)$ master curve of asphalt layers as one of the key input parameters in flexible pavement analysis and design. $\left|\mathrm{E}^{*}\right|$ is a fundamental material property that can characterize the viscoelastic time and temperature dependent behavior of asphalt materials.

In recent years, many efforts have been made for the evaluation and calibration of MEPDG proposed methods in order to implement them in local material, environmental and traffic conditions (Le et al. 2011; Mogawer et al. 2011; Caliendo 2012; Žilionienè et al. 2013; Mai et al. 2014; Kim et al. 2014). Dynamic modulus master curve used in the MEPDG is constructed using dynamic moduli measured in laboratory uniaxial testing on compacted mix samples according to the standard protocols. In addition, there are some predictive models such as Witczak (Andrei et al. 1999), Modified Witczak (Bari, Witczak 2006) and Hirsch (Christensen et al. 2003) that determine $\left|E^{*}\right|$ from some properties of the mixture. Laboratory testing for $\left|\mathrm{E}^{*}\right|$ requires considerable time and is very expensive. In these methods, the effect of confinement on the mechanical properties of asphalt concrete is not considered (Zhao et al. 2014) and in practice, it is not usually possible to have asphalt layers with the thickness required by standard laboratory testing protocols. Hence, if the $\left|\mathrm{E}^{*}\right|$ master curve of an in-service asphalt pavement could be derived directly from a routinely in-situ NDT testing, it would not only save laboratory time and expenses, but it could also lead to a more accurate prediction of remaining life of the pavement.

Falling Weight Deflectometer (FWD) is mainly used to determine structural capacity of in-service pavement layers. Relationship between FWD deflection basin parameters and road pavement structural condition indica-

Corresponding author: Amir Kavussi

E-mail:kavussia@modares.ac.ir 
tors, such as fatigue cracking and permanent deformations were investigated by Talvik and Aavik (2009). Besides, the structural capacity of pavement layers which is tested by FWD could be used for the in-situ assessment of pavement subgrade construction quality (Chai et al. 2015). In addition to FWD, other deflection based equipment such as Rolling Dynamic Deflectometer (RDD) (Nam, Stokoe 2014) and Traffic-Speed Deflectometer (TSD) (Nasimifar et al. 2016) are used to continually evaluate the pavement structural condition at network level PMS. Portable Falling Weight Deflectometer (PFWD) is also widely used for the evaluation of pavement unbound layers and quality control purposes (Kavussi et al. 2010; Rafiei et al. 2012). Under real climatic and traffic conditions, pavement instrumentation has recently become an important tool for monitoring the performance of pavement structures and materials (Čygas et al. 2015). However, the main aim of this work is to develop a practical and simple methodology to determine the dynamic modulus of in-service asphalt layers to use in pavement mechanistic-empirical design method.

\section{Background}

There are two main categories of methods for determining the dynamic modulus master curves of in-service asphalt layers: 1) Methods using dynamic backcalculation of deflection time history data; and 2) Methods using practical laboratory testing and prediction models.

The first category utilizes dynamic backcalculation of FWD deflection data and optimization methods. Kutay et al. (2011) developed a methodology to backcalculate the $\left|E^{*}\right|$ master curve of the asphalt layers using the time history of FWD deflections. In this method, a layered viscoelastic forward algorithm in an iterative backcalculation procedure is used in order to determine linear viscoelastic characteristics of asphalt pavements. This study found that by using deflection time history, it is possible to derive $\mathrm{E}(\mathrm{t})$ (relaxation modulus) and $\left|\mathrm{E}^{*}\right|$ master curve while requiring some modification of the current FWD technology. A new inverse analysis is proposed by Varma et al. (2013a) to backcalculate both linear elastic and viscoelastic properties of pavement layers as well as the asphalt mix time-temperature shift factor. A viscoelastic genetic backcalculation algorithm was developed that uses single FWD drop, time history data, and variation of temperature with the depth of asphalt layer. In addition, this study suggested conducting FWD testing in a set of temperatures to estimate shift factor of asphalt materials (Varma et al. 2013b).

Recently a layered viscoelastic-nonlinear forward model was used to develop a genetic algorithm-based backcalculation scheme by Varma and Kutay (2016). This algorithm uses deflection time history at different test temperatures to backcalculate both the (damaged) $\mathrm{E}(\mathrm{t})$ and $\left|\mathrm{E}^{*}\right|$ master curve of asphalt layers and also the linear and nonlinear (stress dependent) elastic moduli of unbound layers for in-service pavements. Jamrah and
Kutay (2015) also investigated the methods of obtaining asphalt mixture creep compliance $(\mathrm{D}(\mathrm{t}))$ for use in flexible pavement analysis and design using the pavement M-E design software.

In addition to these attempts, data mining tools such as support vector machines, Artificial Neural Network (ANN), decision trees, and meta-algorithms like bagging were also used to predict the non-linear layer moduli of asphalt pavement structures based on the deflection profiles obtained from FWD (Gopalakrishnan et al. 2013). ANN was used for backcalculation of asphalt concrete viscoelastic properties from FWD deflection time history (Gopalakrishnan et al. 2014, 2015). It was found that although this study demonstrates the potential of ANN to predict the $\mathrm{E}(\mathrm{t})$ and $\left|\mathrm{E}^{*}\right|$ master curves from single-drop FWD deflection time history, the current prediction accuracies are not sufficient to recommend these models for practical implementation.

The above mentioned analytical developed methods are yet in research phase and thus, using them in real projects is impractical. The second category is more practical and may be under use by some pavement management agencies. The most well-known and state-of-the-practice method in this category was proposed by the MEPDG (ARA 2004). For rehabilitation projects, MEPDG defines a "damaged" and an "undamaged" modulus and uses a combination of field and laboratory tests for structural evaluation of pavements at three hierarchical levels. At input Level-1, FWD testing is performed and some core samples are taken for extraction analysis purposes. The Witczak or modified Witczak model is used to develop an undamaged master curve utilizing asphalt layer volumetric and bitumen viscosity properties. A damage factor defined as the ratio of backcalculated FWD modulus to predicted value at the same temperature and frequency, is used to distinguish the damaged dynamic modulus master curve from the undamaged one. For Level-2 analysis, instead of FWD testing, the resilient modulus data from cores is used while for Level-3, the damaged modulus is estimated from surface condition rating. The MEPDG method was evaluated by Loulizi et al. (2007) at nine flexible and composite pavements in high performance roads in Virginia, USA. Results showed the ability of this method in predicting the in-situ $\left|E^{*}\right|$ master curve while some disadvantages were reported for input Level-2 analysis.

Other researchers have developed some improved and simple methods based on MEPDG proposed procedure. Biswas and Pellinen (2007) developed a practical methodology for determination of the in-situ dynamic moduli for engineering analysis. They considered the mixture stiffness values measured from simple shear testing (SST) to develop stiffness master curve comparable to the uniaxial dynamic modulus testing. Seo et al. (2013) used experimental tests and numerical simulations to propose a framework to estimate the $\left|E^{*}\right|$ from field stiffness and different depth temperature data. The emphasis of 
this research was on the loading frequency-vehicle speed relationship and was capable of predicting asphalt pavement behavior with varying vehicle speeds. It proposed a converting factor that could estimate the in-situ $\left|E^{*}\right|$ from the undamaged $\left|\mathrm{E}^{*}\right|$ using FWD modulus. Finally, Georgouli et al. (2015) focused on the feasibility of backcalculation procedures to access the $\left|\mathrm{E}^{*}\right|$, by investigating the relationship between the backcalculated in-situ moduli and the laboratory determined $\left|\mathrm{E}^{*}\right|$, using a genetic algorithm. To achieve this goal, FWD testing was applied at several locations along a newly constructed pavement section. Results demonstrated the capability of relationship between field and laboratory data in determining the in-situ $\left|E^{*}\right|$ of asphalt pavements.

\section{Methodology development}

\subsection{Dynamic modulus sigmoidal function}

Dynamic modulus master curve can be presented by the sigmoidal function described by Eqn (1):

$$
\log \left(\left|\mathrm{E}^{*}\right|\right)=\delta+\frac{\alpha}{1+e^{\beta+\gamma \log \left(t_{r}\right)}},
$$

where $\left|\mathrm{E}^{*}\right|$ - asphalt dynamic modulus, psi; $\delta$ - regression parameter $\left(10^{\delta}\right.$ - minimum modulus value); $\alpha$ - specified range from minimum $\left(10^{\delta+\alpha}-\right.$ maximum modulus value); $\beta$ and $\gamma$-regression parameters; $t_{r}-$ reduced time (time of loading at the reference temperature), sec. The fitting parameters $\delta$ and $\alpha$ depend on aggregate gradation, binder and air void contents. The parameters $\beta$ and $\gamma$ depend on the characteristics of the asphalt binder and the magnitude of $\delta$ and $\alpha$. The sigmoidal function describes the time dependency of the modulus at the reference temperature; while the shift factor (Section 2.3) describes the temperature dependency of the asphalt modulus (ARA 2004).

\subsection{Witczak dynamic modulus prediction model}

This model was developed in 1999 based on 2750 data points from 205 asphalt mixtures, including modified and unmodified bitumen grades (Andrei et al. 1999). It predicts $\left|\mathrm{E}^{*}\right|$ at different temperatures as a function of aggregate gradation, mix air voids, effective bitumen content, loading frequency and bitumen stiffness. The bitumen stiffness in the model is expressed in terms of viscosity, which is a function of the temperature. A sigmoidal function can be fitted to this model as expressed in Eqn (2):

$$
\begin{aligned}
& \log \left|\mathrm{E}^{*}\right|=3.750063+0.02932 \rho_{200}-0.001767\left(\rho_{200}\right)^{2}- \\
& 0.002841 \rho_{4}-0.058097 V_{a}-0.802208\left(\frac{V_{\text {beff }}}{V_{\text {beff }}+V_{a}}\right)+ \\
& \frac{3.871977-0.0021 \rho_{4}+0.003958 \rho_{38}-0.000017\left(\rho_{38}\right)^{2}+0.005470 \rho_{34}}{1+e^{(-0.603313-0.313351 \log (f)-0.393532 \log (\eta))}},
\end{aligned}
$$

where $\left|\mathrm{E}^{*}\right|$ - asphalt dynamic modulus, psi; $\eta$-bitumen viscosity, $10^{6}$ Poise; $f$-loading frequency, $\mathrm{Hz} ; \rho_{200}-$ $\%$ passing the $\# 200$ sieve, $\% ; \rho_{4}$ - cumulative $\%$ retained on the \#4 sieve, $\% ; \rho_{34}$ - cumulative $\%$ retained on the $\# 3 / 4$ sieve, $\% ; \quad \rho_{38}-$ cumulative $\%$ retained on the \#3/8 sieve, $\% ; V_{a}$ - air void content, $\%$; and, $V_{\text {beff }}$ - effective bitumen content, $\%$ by volume. This equation has a similar master curve shape corresponding with Eqn (1) for which the parameters are considered as shown below:

$$
\begin{aligned}
\delta= & 3.750063+0.02932 \rho_{200}-0.001767\left(\rho_{200}\right)^{2}- \\
& 0.002841 \rho_{4}-0.058097 V_{a}-0.802208\left(\frac{V_{b e f f}}{V_{b e f f}+V_{a}}\right) ; \\
\alpha= & 3.871977-0.0021 \rho_{4}+0.003958 \rho_{38}- \\
& 0.000017\left(\rho_{38}\right)^{2}+0.005470 \rho_{34} ;
\end{aligned}
$$

$\beta=-0.603313-0.393532 \log (\eta) ;$ and $\gamma=0.313351$.

Having mix volumetric properties and bitumen viscosity parameters, Witczak model is widely used in predicting dynamic modulus of asphalt materials.

\subsection{Bitumen characterization - shift factor}

Bitumen viscosity and shift factor can be determined at various temperatures and at minimum of one frequency using Dynamic Shear Rheometer (DSR) test method, in the following manner (ARA 2004):

Using Eqn (3) for determining the bitumen viscosity at any $\mathrm{G}^{*}$ and associated $\delta$ from DSR:

$$
\eta=\frac{G^{*}}{10}\left(\frac{1}{\sin \delta}\right)^{4.8628}
$$

where $\eta$ - asphalt bitumen viscosity, Pa.s; $G^{*}-$ complex shear modulus of bitumen, $\mathrm{Pa}$; and $\delta$ - bitumen phase angle, degree $\left({ }^{\circ}\right)$. Then, it would be possible to define two viscosity parameters, A and VTS (ASTM D2493M-09:2009):

$$
\log \log (\eta)=A+V T S \log \left(T_{R}\right)
$$

where $\eta$-asphalt bitumen viscosity, $\mathrm{cP} ; T_{R}$ - temperature, Rankine; $A$-regression intercept; and VTS - regression slope of viscosity temperature susceptibility. For calculation of shift factor and also reduced time (or frequency) to be used in development of master curve, Eqns (5) to (7) were proposed:

$$
\begin{gathered}
\log \left(a_{T}\right)=1.255882\left(\log (\eta)-\log \left(\eta_{r}\right)\right) ; \\
\log \left(t_{r}\right)=\log (t)-\log \left(a_{T}\right) ; \\
\log \left(f_{r}\right)=\log (f)+\log \left(a_{T}\right),
\end{gathered}
$$


where $a_{T}$ - shift factor as a function of temperature, $\mathrm{cP}$; $\eta$ - viscosity at temperature of interest, $\mathrm{cP} ; \eta_{r}$ - viscosity at the reference temperature, $\mathrm{cP} ; t$ - time of loading, sec; $t_{r}$ - reduced time, sec; $f$ - frequency of loading, $\mathrm{Hz}$; and $f_{r}$ - reduced frequency, Hz. Eqns (5) to (7) utilize time-temperature superposition principle to transform time (or frequency) to temperature, and vice versa in analysis.

\subsection{Procedure for proposed method to develop in-situ $\left|E^{*}\right|$ master curve}

The principle of proposed method is the modification of the Witczak predicted master curve using FWD deflection data. In this method, predicted modulus is adjusted to the corresponding backcalculated value at the same frequency of FWD loading. The procedure is presented in following steps (Fig. 1):

1. Developing predicted master curve by using volumetric properties and bitumen viscosity data (from the core samples taken from the site) at a reference temperature;

2. Determining reduced frequency of FWD loading $\left(f_{r-F W D}\right)$ at the reference temperature by using Eqn (7) and the field depth temperature of FWD testing;

3. Calculating predicted dynamic modulus for corresponding reduced frequency of FWD loading $\left(\mathrm{E}_{p-F W D}^{*}\right)$;

4. Adjusting predicted dynamic modulus to the measured FWD modulus $\left(E_{m-F W D}\right)$;

5. Generalizing this adjustment to all the other frequencies and constructing the in-situ dynamic modulus master curve for the mentioned reference temperature.

The proposed method assumes that the ratio of FWD backcalculated modulus and the corresponding predicted value is the same in all loading frequencies. This assumption could not be wrong due to the fact that a typical FWD testing applies a load at a fixed duration of about 30 milliseconds. This loading duration is designed in such a way to simulate the effect of a moving load at normal traffic speed (Chatti, Kim 2000). According to previous works (Loulizi et al. 2002; Al-Qadi et al. 2004), this covers normal speeds of the heavy vehicles. Eqn (8) can be used to construct the final in-situ dynamic modulus master curve by fitting the sigmoidal function:

$\log \left(\mid \mathrm{E}_{\text {in-situ }}^{*}\right)=\delta+\frac{\alpha}{1+e^{\beta-\gamma \log \left(f_{r}\right)}}+\log \left(\frac{\mathrm{E}_{m-F W D}}{\mathrm{E}_{p-F W D}^{*}}\right)$,

where $\left|\mathrm{E}_{\text {in-situ }}^{*}\right|-$ in-situ dynamic modulus of asphalt layer, psi; $\mathrm{E}_{m-F W D}-$ FWD backcalculated modulus, psi; $\mathrm{E}_{p-F W D}^{*}-$ predicted dynamic modulus at the corresponding reduced frequency of FWD loading, psi; and $\delta, \alpha, \beta, \gamma$ and $f_{r}$ are as previously defined in Eqns (2) and (7). This equation may be directly used in determination of asphalt dynamic modulus at any frequency of interest. Afterwards, the dynamic modulus master curve for in-service asphalt layers is developed to be used in MEPDG design procedure.

\section{Testing program}

Ten flexible pavement sites were selected in Khuzestan and Kerman provinces in south of Iran to determine insitu dynamic modulus of asphalt layers. All these sites suffer from severe summer temperatures. According to the last sixty years climate records from Iranian Meteorological Organization, in Khuzestan, the highest air temperature varied from $28^{\circ} \mathrm{C}$ in January to $54^{\circ} \mathrm{C}$ in July. In Kerman, it varied from $21{ }^{\circ} \mathrm{C}$ in January to $42{ }^{\circ} \mathrm{C}$ in July (IRIMO 2016). Figure 2 shows the site locations and their general climatic conditions.

General characteristics of the sites are reported in Table 1. The sites were selected from different roads so that they would include pavements with different characteristics with regard to their thickness, number of layers, age and types of base and subbase layers. As it can be seen in this table, for both of the new and rehabilitated pavements, the thickness of their asphalt layers varies from 75 to $400 \mathrm{~mm}$. The base and subbase layers are

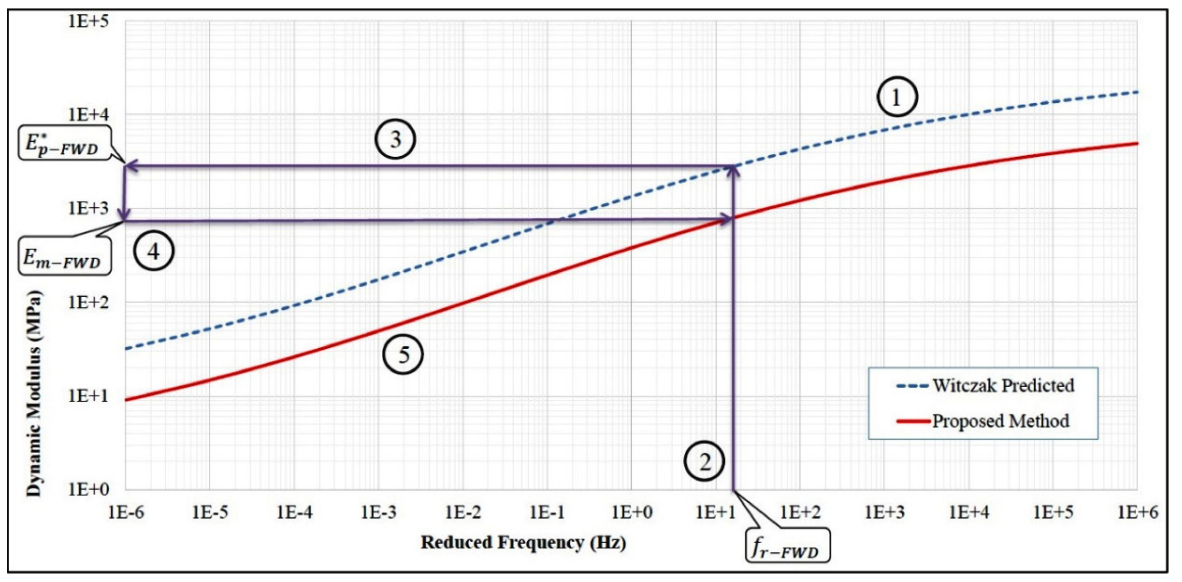

Fig. 1. Procedure of proposed method for development of in-situ $\left|E^{*}\right|$ master curve 


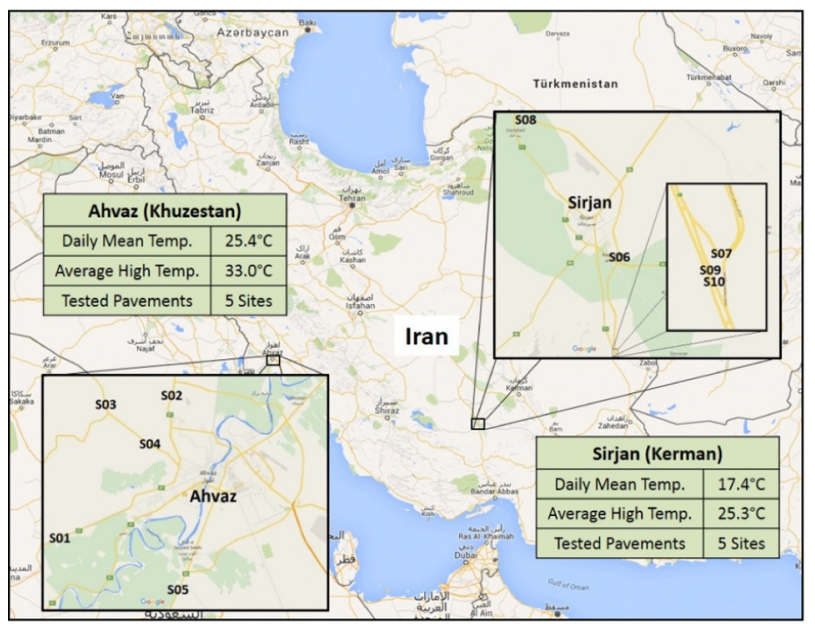

Fig. 2. Location and general climatic conditions of the selected sites in Khuzestan and Kerman

either granular layers or layers stabilized with bitumen emulsion (Site S05). Site S10 was on a bridge deck and had no base and subbase layers. This site contained 400 $\mathrm{mm}$ of asphalt layers on the concrete bridge deck. In sites S09 and S10 that were about 50 meters apart from each other, asphalt mixes and pavement temperatures were the same, while the thickness of their asphalt layers was different and one of them had no unbound layers. The age of the pavement sites varied from 2 weeks to 25 years.

\subsection{FWD testing}

In this work a Dynatest 8000 FWD device was used to apply loading on pavements and to measure deflections at various locations. In order to accurately determine field moduli of various layers, four different stress levels were applied. More geophones were located near the center of loading plate in order to measure responses of asphalt layers more accurately. The testing setup conditions are reported in Table 2.

Table 2. FWD testing setup conditions

\begin{tabular}{l|c}
\hline \multicolumn{1}{c|}{ Parameter } & Value \\
\hline Stress $(\mathrm{kPa})$ & $600,900,1300$ and 1900 \\
\hline Plate Diameter $(\mathrm{mm})$ & 300 \\
\hline Number of Geophones & 9 \\
\hline Geophone Position (cm) & $\begin{array}{c}0,20,30,40,50,60,90, \\
120 \text { and 150 }\end{array}$ \\
\hline Number of Testing at Each Site & $\begin{array}{c}\text { Every 30 min from 6:00 } \\
\text { a. m. to 6:00 p. m. }\end{array}$ \\
\hline
\end{tabular}

FWD testing and temperature measurements at each testing site were conducted at half an hour intervals during a full working day. In addition, temperatures were measured at depths of half and one third of asphalt layers. Air and surface temperatures were automatically recorded by FWD device every half an hour. Hence, FWD measured data were obtained where the asphalt layer depth

Table 1. General characteristics of the pavement sites

\begin{tabular}{|c|c|c|c|c|c|c|c|c|c|c|c|c|}
\hline \multirow{2}{*}{ 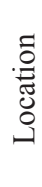 } & \multirow{2}{*}{$\begin{array}{l}\text { Site } \\
\text { ID }\end{array}$} & \multirow{2}{*}{ Road Name } & \multirow{2}{*}{$\begin{array}{l}\text { Pavement } \\
\text { Type }\end{array}$} & \multirow{2}{*}{$\begin{array}{l}\text { Pavement } \\
\text { Age }\end{array}$} & \multirow{2}{*}{$\begin{array}{c}\text { Total } \\
\text { Thickness } \\
\text { of Asphalt } \\
\text { Layers } \\
(\mathrm{mm})\end{array}$} & \multicolumn{4}{|c|}{$\begin{array}{c}\text { Thickness of Asphalt } \\
\text { Sublayers }(\mathrm{mm})\end{array}$} & \multirow{2}{*}{$\begin{array}{c}\text { Total } \\
\text { Thickness } \\
\text { of Base and } \\
\text { Subbase } \\
\text { Layers }(\mathrm{mm})\end{array}$} & \multirow{2}{*}{$\begin{array}{c}\text { Bitumen } \\
\text { Grade } \\
\text { (Pen) }\end{array}$} & \multirow{2}{*}{$\begin{array}{l}\text { Type of } \\
\text { Base \& } \\
\text { Subbase }\end{array}$} \\
\hline & & & & & & 1 & 2 & 3 & 4 & & & \\
\hline \multirow{5}{*}{ 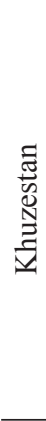 } & S01 & $\begin{array}{l}\text { Ahvaz - } \\
\text { Shirin Shahr }\end{array}$ & New & 2 Weeks & 75 & 75 & - & - & - & 300 & $60 / 70$ & Granular \\
\hline & S02 & $\begin{array}{l}\text { Ahvaz - } \\
\text { Shush }\end{array}$ & New & 4 Years & 95 & 95 & - & - & - & 345 & $60 / 70$ & Granular \\
\hline & S03 & $\begin{array}{l}\text { Ahvaz - } \\
\text { Hamidiyeh (1) }\end{array}$ & Rehabilitated & 5 Years & 115 & 115 & - & - & - & 215 & $40 / 50$ & Granular \\
\hline & S04 & $\begin{array}{l}\text { Ahvaz - } \\
\text { Hamidiyeh (2) }\end{array}$ & Rehabilitated & 10 Years & 190 & 40 & 70 & 80 & - & 200 & $60 / 70$ & Granular \\
\hline & S05 & $\begin{array}{l}\text { Ahvaz - } \\
\text { Khorramshahr }\end{array}$ & Rehabilitated & 25 Years & 220 & 60 & 40 & 120 & - & 120 & $60 / 70$ & Stabilized \\
\hline \multirow{5}{*}{ 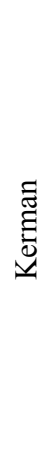 } & S06 & Sirjan - Baft & New & 6 Months & 120 & 60 & 60 & - & - & 250 & $60 / 70$ & Granular \\
\hline & S07 & $\begin{array}{l}\text { Sirjan } \\
\text { Expressway }\end{array}$ & New & 2 Years & 120 & 60 & 60 & - & - & 320 & $60 / 70$ & Granular \\
\hline & S08 & $\begin{array}{l}\text { Sirjan - } \\
\text { Shahr-e Babak }\end{array}$ & $\begin{array}{l}\text { New } \\
\text { Overlaid }\end{array}$ & 1 Years & 145 & 45 & 50 & 50 & - & 305 & $60 / 70$ & Granular \\
\hline & S09 & $\begin{array}{l}\text { Sirjan - } \\
\text { Bandar Abbas } \\
\text { (1) }\end{array}$ & Rehabilitated & 15 Years & 300 & 60 & 60 & 80 & 100 & 220 & $60 / 70$ & Granular \\
\hline & $\mathrm{S} 10$ & $\begin{array}{l}\text { Sirjan - } \\
\text { Bandar Abbas } \\
\text { (2) }\end{array}$ & Rehabilitated & 15 Years & 400 & 60 & 60 & 80 & 200 & Bridge Deck & $60 / 70$ & Concrete \\
\hline
\end{tabular}


temperature ranged from $30{ }^{\circ} \mathrm{C}$ to $50{ }^{\circ} \mathrm{C}$ for each pavement site. Figure 3 shows a typical FWD testing site and the drilled holes for measurement of asphalt layer temperatures with digital thermometers. As it can be seen in this figure, FWD loading was conducted in outer wheel path with no cracking (according to the MEPDG instruction) and temperatures were measured just near the loading area.

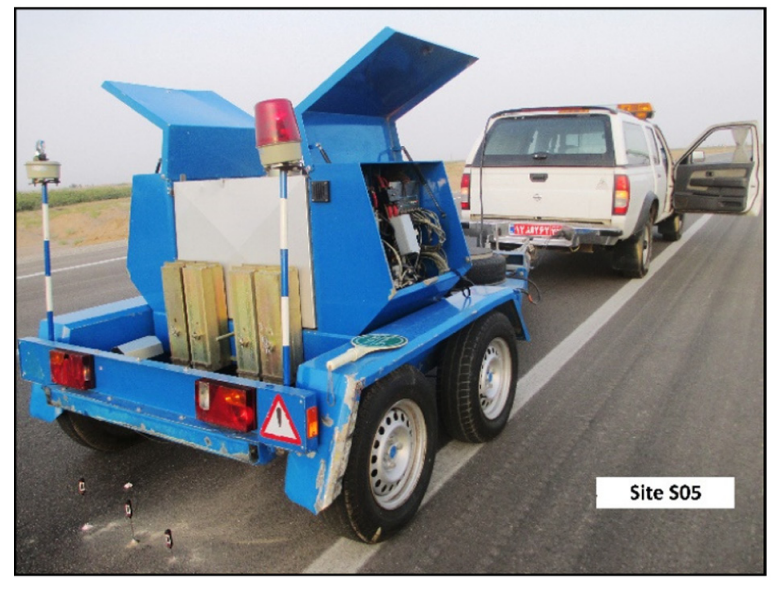

Fig. 3. FWD testing and depth temperature measurements of asphalt layers on a pavement site

\subsection{Laboratory mixture volumetric properties and bitumen DSR testing}

Mix volumetric properties and bitumen viscosity characterization were used to estimate the undamaged dynamic modulus master curve using the Witczak model. Core samples taken from the field were extracted and their bitumen was separated. Since some sample cores were made up of several asphalt layers, they were cut before extraction. Aggregate gradation was done and the mix volumetric parameters were determined. In addition, DSR testing was conducted on the extracted bitumen. For accurate characterization of bitumen viscosity parameters, DSR testing was done at varying temperatures from 5 to $60{ }^{\circ} \mathrm{C}$ with $1{ }^{\circ} \mathrm{C}$ intervals and at a standard frequency of $1.59 \mathrm{~Hz}(10 \mathrm{rad} / \mathrm{s})$.

\section{Results and discussion}

\subsection{FWD backcalculated moduli}

Backcalculated moduli of asphalt layers (considered as a single layer) were determined from FWD deflection data using ELMOD backcalculation software (Dynatest International A/S 2014). For this purpose, the pavement was modeled as a system of three layers. All asphalt layers were grouped into one layer. The base and subbase layers were combined into the second layer and the subgrade was defined as the third layer with infinite thickness. The backcalculated moduli of asphalt layers in all testing sites at the temperatures of $30,35,40$ and $45^{\circ} \mathrm{C}$ are presented in Table 3. The maximum moduli were obtained for Site S05 (a site with stabilized base) which had the oldest pavement section. Hence, the effect of aging and asphalt stiffening has been reflected on backcalculation modulus from FWD testing. The minimum moduli were obtained for Site S01 which was just two weeks old and consisted of a 75-mm thickness of asphalt layer.

\subsection{Witczak predicted dynamic modulus master curves}

Due to the high temperature of testing areas, reference temperature was selected to be $35{ }^{\circ} \mathrm{C}$ for constructing dynamic modulus master curves. Predicted (undamaged) dynamic modulus master curves were developed at this temperature for all pavement sites using Witczak model based on mix volumetric properties and bitumen viscosity parameters. Table 4 reports these volumetric properties and bitumen characterization values for all testing samples. In this case, some sites consisted of a single asphalt layer while others consisted of several layers. Since a single FWD modulus was determined for each site, the dynamic moduli obtained from Witczak prediction model for sites with multiple asphalt layers were combined to calculate a single modulus using Eqn (9) (Ullidtz 1998):

$$
E_{C M}=\left(\frac{\sum_{i=1}^{n} h_{i} \times \sqrt[3]{E_{i}}}{\sum_{i=1}^{n} h_{i}}\right)^{3},
$$

where $E_{C M}$ - combined modulus of all asphalt layers, $\mathrm{MPa} ; E_{i}$-modulus of layer $i, \mathrm{MPa} ; h_{i}$ - thickness of layer $i, \mathrm{~mm}$; and, $n$ - number of asphalt layers. As an example, dynamic modulus master curves of individual layers and the combined one for Site S05 are shown in Figure 4. For all frequencies, the maximum predicted dynamic moduli were obtained for Site S05; while minimum values were obtained for Site S01 due to their asphalt layer characteristics explained earlier.

Table 3. FWD backcalculated moduli results $(\mathrm{MPa})$

\begin{tabular}{crrrrrrrrrr}
\hline \multirow{2}{*}{$\begin{array}{c}\text { Layer Depth } \\
\text { Temperature }\left({ }^{\circ} \mathrm{C}\right)\end{array}$} & S01 & S02 & S03 & S04 & S05 & S06 & S07 & S08 & S09 & S10 \\
\hline 30 & 1608 & 6998 & 4511 & 6780 & 15615 & 6043 & 4538 & 4502 & 4015 & 11375 \\
\hline 35 & 1425 & 6112 & 3948 & 5688 & 12430 & 5150 & 3633 & 3994 & 3134 & 8023 \\
\hline 40 & 1243 & 5225 & 3385 & 4596 & 9244 & 4258 & 2729 & 3487 & 2252 & 4672 \\
\hline 45 & 1060 & 4338 & 2822 & 3504 & 6058 & 3365 & 1824 & 2979 & N/A & N/A \\
\hline
\end{tabular}


Table 4. Mix volumetric properties and asphalt bitumen viscosity parameters for all samples

\begin{tabular}{|c|c|c|c|c|c|c|c|c|}
\hline \multirow{2}{*}{ Sample ID } & \multicolumn{6}{|c|}{ Mix Volumetric Properties } & \multicolumn{2}{|c|}{ Bitumen Viscosity Parameters } \\
\hline & $\rho_{200}$ & $\rho_{4}$ & $\rho_{38}$ & $\rho_{34}$ & $V_{a}$ & $V_{\text {beff }}$ & $A$ & VTS \\
\hline S01L1 & 5.0 & 52.0 & 22.0 & 0.0 & 6.2 & 8.5 & 7.8108 & -2.5217 \\
\hline S02L1 & 7.9 & 33.0 & 11.0 & 1.0 & 5.7 & 7.1 & 7.0816 & -2.2418 \\
\hline S03L1 & 6.4 & 49.0 & 27.0 & 0.0 & 6.6 & 7.0 & 5.9842 & -1.8270 \\
\hline S04L1 & 4.1 & 47.9 & 28.9 & 3.7 & 6.3 & 6.2 & 5.5108 & -1.6526 \\
\hline S04L2 & 3.7 & 40.6 & 18.9 & 4.8 & 5.9 & 6.4 & 5.6345 & -1.6993 \\
\hline S04L3 & 6.2 & 60.3 & 37.8 & 13.0 & 5.2 & 7.7 & 6.1744 & -1.9060 \\
\hline S05L1 & 8.7 & 41.0 & 19.7 & 0.8 & 5.7 & 8.2 & 6.4522 & -1.9826 \\
\hline S05L2 & 8.7 & 36.8 & 15.2 & 0.0 & 3.0 & 8.8 & 6.0357 & -1.8300 \\
\hline S05L3 & 4.9 & 55.5 & 34.3 & 7.0 & 3.2 & 8.2 & 6.2332 & -1.9116 \\
\hline S06L1 & 12.0 & 32.0 & 19.0 & 5.0 & 5.5 & 9.4 & 7.7897 & -2.5004 \\
\hline S06L2 & 7.2 & 32.0 & 11.0 & 0.0 & 4.5 & 11.0 & 8.7667 & -2.8616 \\
\hline S07L1 & 8.5 & 32.0 & 7.0 & 0.0 & 6.9 & 7.6 & 8.3994 & -2.7266 \\
\hline S07L2 & 7.6 & 35.1 & 19.9 & 6.6 & 6.3 & 7.5 & 7.2200 & -2.2918 \\
\hline S08L1 & 7.7 & 34.4 & 5.3 & 0.0 & 4.0 & 7.1 & 7.7827 & -2.5041 \\
\hline S08L2 & 7.8 & 46.0 & 30.0 & 5.0 & 7.1 & 5.3 & 8.3506 & -2.7099 \\
\hline S08L3 & 8.2 & 35.0 & 19.0 & 2.0 & 8.2 & 6.4 & 8.6255 & -2.8089 \\
\hline S09L1 & 7.0 & 34.2 & 15.1 & 0.0 & 2.1 & 9.5 & 6.2579 & -1.9171 \\
\hline S09L2 & 8.7 & 37.8 & 24.3 & 0.0 & 2.1 & 10.6 & 6.2400 & -1.9175 \\
\hline S09L3 & 4.4 & 37.0 & 20.0 & 1.0 & 4.2 & 7.3 & 8.0928 & -2.6159 \\
\hline S09L4 & 6.2 & 41.0 & 31.0 & 3.0 & 5.5 & 6.4 & 7.3857 & -2.3610 \\
\hline S10L1 & 7.0 & 34.2 & 15.1 & 0.0 & 2.1 & 9.5 & 6.2579 & -1.9171 \\
\hline S10L2 & 8.7 & 37.8 & 24.3 & 0.0 & 2.1 & 10.6 & 6.2400 & -1.9175 \\
\hline S10L3 & 4.4 & 37.0 & 20.0 & 1.0 & 4.2 & 7.3 & 8.0928 & -2.6159 \\
\hline S10L4 & 6.2 & 41.0 & 31.0 & 3.0 & 5.5 & 6.4 & 7.3857 & -2.3610 \\
\hline
\end{tabular}

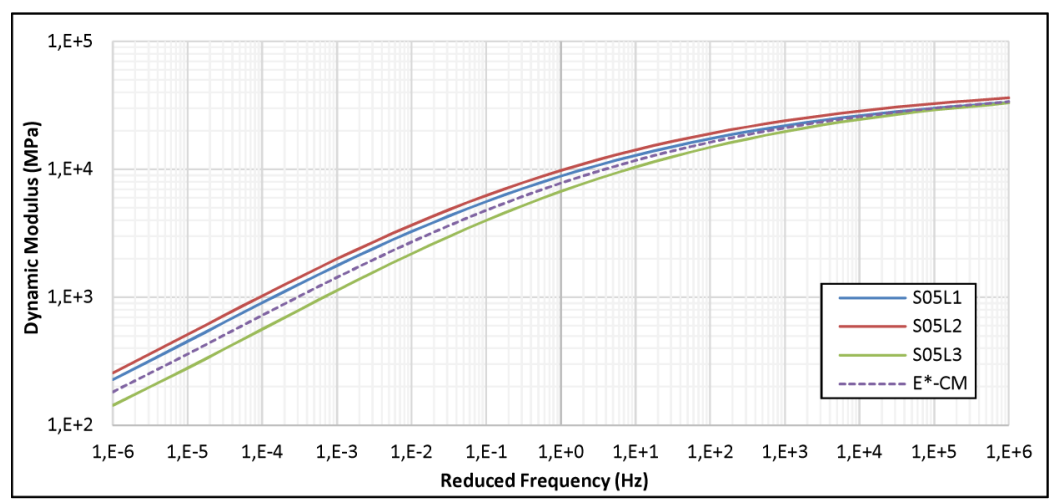

Fig. 4. Predicted dynamic modulus master curves of individual layers and combined one for Site S05

\subsection{In-situ dynamic modulus master curves}

In-situ $\left|E^{*}\right|$ master curves were developed using Eqn (8) according to the proposed procedure in Section 2.4. Reference temperature was selected to be $35^{\circ} \mathrm{C}$ and equivalent frequency of FWD was obtained from its loading time histories. An average loading time of 0.030 s was considered and the frequency which was calculated us- ing Equation " $f_{F W D}=1 / 2 \Delta t$ " (Lytton et al. 1990) was 16.67 Hz. Predicted dynamic modulus master curves were adjusted to FWD moduli and the in-situ dynamic modulus master curves were obtained. Figure 5 shows the in-situ $\left|E^{*}\right|$ master curve for Site S01 using proposed methodology. FWD measured moduli at mentioned temperatures, predicted Witczak dynamic modulus and insitu MEPDG Level-1 master curves are also shown in 


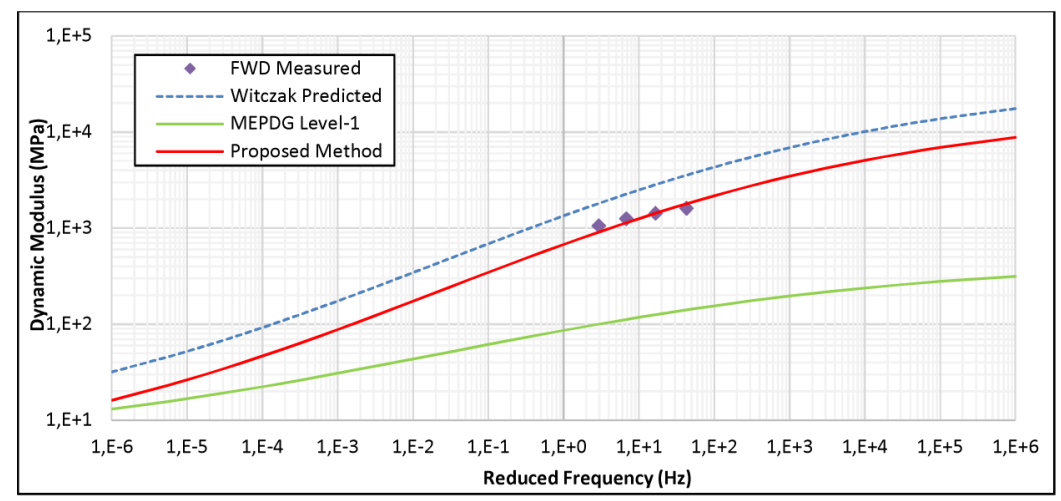

Fig. 5. Dynamic modulus master curves of asphalt layer for Site S01

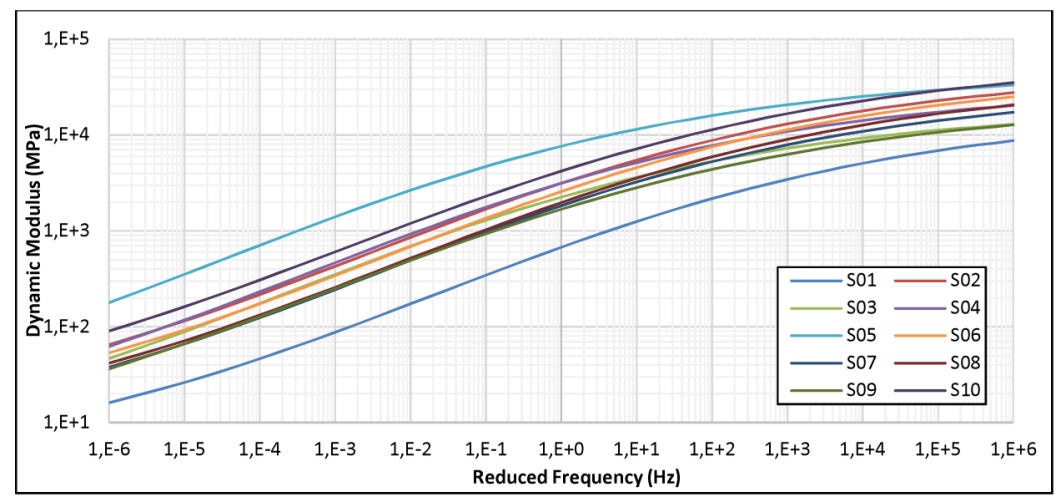

Fig. 6. In-situ dynamic modulus master curves for all sites using proposed method in this study

this figure. In addition, in-situ $\left|E^{*}\right|$ master curves for all pavement sites are shown in Figure 6.

\subsection{Evaluation of proposed method and comparison with MEPDG}

For evaluating efficiency of the proposed method, a comparison was made using the MEPDG as a state-of-thepractice method. Level-1 analysis of MEPDG was selected for comparison due to its high accuracy. This level uses FWD deflection data to calculate damage and then by substituting one of the fitting parameters ( $\alpha^{\prime}$ instead of $\alpha$ ) in the sigmoidal function, damaged master curve is derived. Dynamic modulus master curve developed by MEPDG procedure is shown in Figure 5 together with predicted (undamaged) and proposed master curves. As it can be seen in this figure, in-situ $\left|E^{*}\right|$ values resulted by these two methods are different in all frequencies. Although in very low frequencies they are approximately close to each other, these differences are increased extremely in high frequencies (note that the curves are drawn in logarithmic scale).

This comparison was made in all pavement sites and similar results were obtained. Table 5 shows the comparison results between the proposed and the MEPDG methods. For this comparison, measured FWD backcalculated moduli obtained in different temperatures were considered and corresponding reduced frequency of loading temperatures were calculated. In-situ dynamic moduli using both the MEPDG and the proposed methods are presented in reduced frequencies in this table. Comparison of results showed that average error between measured FWD moduli and those determined by MEPDG method is about $77.2 \%$ while this average error is only $8.9 \%$ for in-situ moduli determined from proposed method in this study. This issue can be seen for Site S01 in Figure 5.

In all pavements, proposed method had the same trend with the main predicted master curves and showed closer values in comparison with MEPDG in all frequencies. Whereas the MEPDG values in extremely high frequencies were very far from the Witczak predicted master curves. This is one of the disadvantages of MEPDG method especially in evaluation of new pavements. Another point to notice is that the final determined dynamic modulus for corresponding frequency of FWD, is significantly different from the measured value in MEPDG; whereas the proposed method for which the determined in-situ dynamic modulus is equal to the measured value, does not suffer from such a problem. In addition, in MEPDG method it is necessary to first calculate the damage factor and then constructing the damaged master curve; while in this proposed method, final in-situ master curve can be developed directly without any need for damage factor or substituting any other parameter in the final master curve sigmoidal function. 
Table 5. Comparison between the proposed and MEPDG methods at different layer temperatures

\begin{tabular}{|c|c|c|c|c|c|c|c|c|}
\hline \multirow{2}{*}{$\begin{array}{l}\text { Site } \\
\text { ID }\end{array}$} & \multirow{2}{*}{$\begin{array}{l}\text { Layer Depth } \\
\text { Temperature } \\
\quad\left({ }^{\circ} \mathrm{C}\right)\end{array}$} & \multirow{2}{*}{$\begin{array}{c}\text { Reduced } \\
\text { Frequency @ } \\
35^{\circ} \mathrm{C}(\mathrm{Hz})\end{array}$} & \multirow{2}{*}{$\begin{array}{l}\text { Witczak Model } \\
\text { Predicted }\left|\mathrm{E}^{*}\right| \\
\quad(\mathrm{MPa})\end{array}$} & \multirow{2}{*}{$\begin{array}{c}\text { Measured } \\
\text { FWD Modulus } \\
(\mathrm{MPa})\end{array}$} & \multicolumn{2}{|c|}{ MEPDG Level-1 } & \multicolumn{2}{|c|}{$\begin{array}{l}\text { Proposed Method } \\
\text { (This Study) }\end{array}$} \\
\hline & & & & & $\left|\mathrm{E}^{*}\right|(\mathrm{MPa})$ & Error $(\%)$ & $\left|\mathrm{E}^{*}\right|(\mathrm{MPa})$ & $\begin{array}{c}\text { Error } \\
(\%)\end{array}$ \\
\hline \multirow{4}{*}{ S01 } & 30 & 43.01 & 3551 & 1608 & 140 & 91.3 & 1790 & 11.3 \\
\hline & 35 & 16.67 & 2827 & 1425 & 125 & 91.2 & 1425 & 0.0 \\
\hline & 40 & 6.81 & 2253 & 1243 & 112 & 91.0 & 1136 & 8.6 \\
\hline & 45 & 2.92 & 1801 & 1060 & 100 & 90.6 & 908 & 14.4 \\
\hline \multirow{4}{*}{ S02 } & 30 & 41.81 & 7481 & 6998 & 6974 & 0.3 & 7406 & 5.8 \\
\hline & 35 & 16.67 & 6174 & 6112 & 5767 & 5.6 & 6112 & 0.0 \\
\hline & 40 & 6.97 & 5083 & 5225 & 4757 & 8.9 & 5032 & 3.7 \\
\hline & 45 & 3.04 & 4182 & 4338 & 3921 & 9.6 & 4140 & 4.6 \\
\hline \multirow{4}{*}{ S03 } & 30 & 37.86 & 9938 & 4511 & 174 & 96.1 & 4547 & 0.8 \\
\hline & 35 & 16.67 & 8629 & 3948 & 164 & 95.9 & 3948 & 0.0 \\
\hline & 40 & 7.62 & 7466 & 3385 & 153 & 95.5 & 3416 & 0.9 \\
\hline & 45 & 3.60 & 6443 & 2822 & 143 & 94.9 & 2948 & 4.5 \\
\hline \multirow{4}{*}{ S04 } & 30 & 36.31 & 9855 & 6780 & 830 & 87.8 & 6560 & 3.2 \\
\hline & 35 & 16.67 & 8544 & 5688 & 755 & 86.7 & 5688 & 0.0 \\
\hline & 40 & 7.92 & 7388 & 4596 & 685 & 85.1 & 4919 & 7.0 \\
\hline & 45 & 3.89 & 6377 & 3504 & 622 & 82.3 & 4246 & 21.2 \\
\hline \multirow{4}{*}{ S05 } & 30 & 41.81 & 14478 & 15615 & 12468 & 20.2 & 14200 & 9.1 \\
\hline & 35 & 16.67 & 12674 & 12430 & 10941 & 12.0 & 12431 & 0.0 \\
\hline & 40 & 6.94 & 11036 & 9244 & 9552 & 3.3 & 10824 & 17.1 \\
\hline & 45 & 3.01 & 9567 & 6058 & 8303 & 37.1 & 9383 & 54.9 \\
\hline \multirow{4}{*}{ S06 } & 30 & 49.15 & 6335 & 6043 & 7632 & 26.3 & 6504 & 7.6 \\
\hline & 35 & 16.67 & 5016 & 5150 & 6006 & 16.6 & 5150 & 0.0 \\
\hline & 40 & 6.03 & 3960 & 4258 & 4713 & 10.7 & 4066 & 4.5 \\
\hline & 45 & 2.31 & 3125 & 3365 & 3697 & 9.9 & 3208 & 4.7 \\
\hline \multirow{4}{*}{ S07 } & 30 & 46.13 & 6826 & 4538 & 640 & 85.9 & 4513 & 0.5 \\
\hline & 35 & 16.67 & 5495 & 3633 & 554 & 84.7 & 3633 & 0.0 \\
\hline & 40 & 6.38 & 4412 & 2729 & 479 & 82.4 & 2917 & 6.9 \\
\hline & 45 & 2.58 & 3541 & 1824 & 414 & 77.3 & 2341 & 28.3 \\
\hline \multirow{4}{*}{ S08 } & 30 & 48.40 & 6441 & 4502 & 1477 & 67.2 & 5060 & 12.4 \\
\hline & 35 & 16.67 & 5084 & 3994 & 1227 & 69.3 & 3994 & 0.0 \\
\hline & 40 & 6.11 & 4004 & 3487 & 1017 & 70.8 & 3145 & 9.8 \\
\hline & 45 & 2.38 & 3154 & 2979 & 844 & 71.7 & 2478 & 16.8 \\
\hline \multirow{4}{*}{ S09 } & 30 & 42.78 & 8793 & 4015 & 143 & 96.4 & 3763 & 6.3 \\
\hline & 35 & 16.67 & 7323 & 3134 & 133 & 95.8 & 3134 & 0.0 \\
\hline & 40 & 6.83 & 6084 & 2252 & 122 & 94.6 & 2604 & 15.6 \\
\hline & 45 & N/A & N/A & N/A & N/A & N/A & N/A & N/A \\
\hline \multirow{5}{*}{ S10 } & 30 & 42.53 & 8100 & 11375 & 33669 & 196.0 & 9701 & 14.7 \\
\hline & 35 & 16.67 & 6698 & 8023 & 26906 & 235.4 & 8024 & 0.0 \\
\hline & 40 & 6.87 & 5529 & 4672 & 21450 & 359.1 & 6625 & 41.8 \\
\hline & 45 & N/A & N/A & N/A & N/A & N/A & N/A & N/A \\
\hline & \multicolumn{4}{|c|}{ Average Error (\%) } & \multicolumn{2}{|c|}{77.2} & \multicolumn{2}{|c|}{8.9} \\
\hline
\end{tabular}




\section{Conclusions}

A new simple and practical methodology was proposed to develop dynamic modulus master curves of in-service asphalt layers for use in pavement mechanistic-empirical rehabilitation procedure. Ten asphalt pavement sites were selected and results of using proposed method were compared with state-of-the-practice MEPDG procedure. Following conclusions were obtained:

- Using proposed method, it is possible to simply develop dynamic modulus master curves of in-service asphalt layers by conducting a routinely FWD testing in any environmental temperature.

- Proposed in-situ dynamic modulus master curve had the same trend with the main predicted master curve and showed closer values in comparison with MEPDG in all frequencies.

- In-situ $\left|E^{*}\right|$ values resulted by both proposed and MEPDG methods are different in all frequencies. Although in very low frequencies they are approximately close to each other, but these differences are extremely increased in high frequencies.

- The final determined dynamic modulus for corresponding frequency of FWD by MEPDG, is significantly different from the measured value; while this problem doesn't exist in the proposed method and the determined in-situ dynamic modulus is the same as the measured one.

- Final in-situ dynamic modulus master curve can be developed directly without the need for calculating any damage factor or substituting any other parameter in the master curve sigmoidal function.

\section{References}

Al-Qadi, I. L.; Loulizi, A.; Elseifi, M.; Lahouar, S. 2004. The Virginia Smart Road: the impact of pavement instrumentation on understanding pavement performance, Journal of Association of Asphalt Paving Technology 83: 427-466.

Andrei, D.; Witczak, M. W.; Mirza, M. W. 1999. Development of a revised predictive model for the dynamic (complex) modulus of asphalt mixtures. Inter Team Technical Report. Prepared for the NCHRP 1-37A project. Department of Civil Engineering, University of Maryland, College Park, MD.

ARA. 2004. Guide for mechanistic-empirical design of new and rehabilitated pavement structures. NCHRP 1-37A, National Cooperative Highway Research Program, Transportation Research Board, National Research Council, Washington, D.C.

ASTM D2493M-09:2009 Standard viscosity-temperature chart for asphalts. West Conshohocken, PA. https://doi.org/10.1520/D2493 D2493M-09

Bari, J.; Witczak, M. W. 2006. Development of a new revised version of the Witczak $\mathrm{E}^{*}$ predictive model for hot mix asphalt mixtures, Journal of Association of Asphalt Paving Technology 75: 381-417.

Biswas, K. G.; Pellinen, T. K. 2007. Practical methodology of determining the in situ dynamic (complex) moduli for engineering analysis, Journal of Materials in Civil Engineering 19(6): 508-514.

https://doi.org/10.1061/(ASCE)0899-1561(2007)19:6(508)
Caliendo, C. 2012. Local calibration and implementation of the mechanistic-empirical pavement design guide for flexible pavement design, Journal of Transportation Engineering 138(3): 348-360.

https://doi.org/10.1061/(ASCE)TE.1943-5436.0000328

Chai, G. W.; Staden, R.; Loo, Y. 2015. In situ assessment of pavement subgrade using Falling Weight Deflectometer, Journal of Testing and Evaluation 43(1): 140-148. https://doi.org/10.1520/JTE20130149

Chatti, K.; Kim, T. K. 2000. Effect of frequency-dependent asphalt concrete layer moduli on pavement response, in S. D. Tayabji, E. O. Lukanen (Eds.). Nondestructive testing of pavements and backcalculation of moduli. Vol. 3, ASTM STP 1375. American Society for Testing and Materials, West Conshohocken, PA., 365-382.

https://doi.org/10.1520/STP14778S

Christensen, D. W.; Pellinen, T.; Bonaquist, R. F. 2003. Hirsch model for estimating the modulus of asphalt concrete, Journal of the Association of Asphalt Paving Technologists 72: 97-121.

Čygas, D.; Laurinavičius, A.; Paliukaite, M.; Motiejūnas, A.; Žiliūte, L.; Vaitkus, A. 2015. Monitoring the mechanical and structural behavior of the pavement structure using electronic sensors, Computer-Aided Civil and Infrastructure Engineering 30(4): 317-328.

https://doi.org/10.1111/mice.12104

Dynatest International A/S. 2014. ELMOD user's manual (ELMOD5). Dynatest Engineering A/S, A/S Reg. No. 63.866, Denmark.

Georgouli, K.; Pomoni, M.; Cliatt, B.; Loizos, A. 2015. A simplified approach for the estimation of HMA dynamic modulus for in service pavements, in $6^{\text {th }}$ International Conference "Bituminous Mixtures and Pavements", 10-12 June 2015, Thessaloniki, Greece.

Gopalakrishnan, K.; Agrawal, A.; Ceylan, H.; Kim, S.; Choudhary, A. 2013. Knowledge discovery and data mining in pavement inverse analysis, Transport 28(1): 1-10. https://doi.org/10.3846/16484142.2013.777941

Gopalakrishnan, K.; Kim, S.; Ceylan, H.; Kaya, O. 2014. Development of asphalt dynamic modulus master curve using falling weight deflectometer measurements. Technical Report: TR-659. Institute for Transportation, Iowa State University.

Gopalakrishnan, K.; Kim, S.; Ceylan, H.; Kaya, O. 2015. Use of neural networks enhanced differential evolution for backcalculating asphalt concrete viscoelastic properties from falling weight deflectometer time series data, in $6^{\text {th }} I n$ ternational Conference "Bituminous Mixtures and Pavements", 10-12 June 2015, Thessaloniki, Greece.

IRIMO. 2016. Climate data reports 1951-2014. I.R. of Iran Meteorological Organization [online], [cited 25 November 2016]. Available from Internet: http://www.irimo.ir/eng/wd/720-Products-Services.html

Jamrah, A.; Kutay, M. E. 2015. Investigation of different methods for obtaining asphalt mixture creep compliance for use in pavement mechanistic-empirical design software, Transportation Research Record: Journal of the Transportation Research Board 2524: 100-109. https://doi.org/10.3141/2524-10

Kavussi, A.; Rafiei, K.; Yasrobi, S. 2010. Evaluation of PFWD as potential quality control tool of pavement layers, Journal of Civil Engineering and Management 16(1): 123129. https://doi.org/10.3846/jcem.2010.11

Kim, S.; Ceylan, H.; Ma, D.; Gopalakrishnan, K. 2014. Calibration of pavement ME design and mechanistic-empirical pavement design guide performance prediction models for Iowa pavement systems, Journal of Transportation Engineering 140(10): 04014052.

https://doi.org/10.1061/(ASCE)TE.1943-5436.0000704 
Kutay, E.; Chatti, K.; Lei, L. 2011. Backcalculation of dynamic modulus master curve from Falling Weight Deflectometer surface deflections, Transportation Research Record: Journal of the Transportation Research Board 2227: 8796. https://doi.org/10.3141/2227-10

Le, A. T.; Lee, H. J.; Park, H. M.; Kim, T. W. 2011. Development of Korean pavement design guide for asphalt pavements based on the mechanistic-empirical design principle, The Baltic Journal of Road and Bridge Engineering 6(3): 169-176. https://doi.org/10.3846/bjrbe.2011.22

Loulizi, A.; Al-Qadi, I. L.; Lahouar, S.; Freeman, T. E. 2002. Measurement of vertical compressive stress pulse in flexible pavements and its representation for dynamic loading tests, Transportation Research Record: Journal of the Transportation Research Board 1816: 125-136. https://doi.org/10.3141/1816-14

Loulizi, A.; Flintsch, G. W.; McGhee, K. 2007. Determination of the in-place hot-mix asphalt layer modulus for rehabilitation projects by a mechanistic-empirical procedure, Transportation Research Record: Journal of the Transportation Research Board 2037: 53-62. https://doi.org/10.3141/2037-05

Lytton, R. L.; Germann, F. P.; Chou, Y. J.; Stoffels, S. M. 1990. Determining asphaltic concrete pavement structural properties by nondestructive testing. National Cooperative Highway Research Program (NCHRP), Report 327. Transportation Research Board, Washington D.C.

Mai, D.; Turochy, R.; Timm, D. 2014. Sensitivity of flexible pavement thickness to traffic factors in mechanistic-empirical pavement design, Journal of Transportation Engineering 140(2): 04013005.

https://doi.org/10.1061/(ASCE)TE.1943-5436.0000628

Mogawer, W. S.; Austerman, A. J.; Daniel, J. S.; Zhou, F.; Bennert, T. 2011. Evaluation of the effects of hot mix asphalt density on mixture fatigue performance, rutting performance and MEPDG distress predictions, International Journal of Pavement Engineering 12(2): 161-175. https://doi.org/10.1080/10298436.2010.546857

Nam, B.; Stokoe, K. H. 2014. Improved rolling dynamic deflectometer for continuous pavement deflection measurements, Journal of Testing and Evaluation 42(2): 1-16. https://doi.org/10.1520/JTE20120262

Nasimifar, M.; Thyagarajan, S.; Siddharthan, R.; Sivaneswaran, N. 2016. Robust deflection indices from traffic-speed deflectometer measurements to predict critical pavement responses for network-level pavement management sys- tem application, Journal of Transportation Engineering 142(3): 04016004.

https://doi.org/10.1061/(ASCE)TE.1943-5436.0000832

Rafiei, K.; Kavussi, A.; Yasrobi, S. 2012. Construction quality control of unbound layers based on stiffness modulus criteria, Journal of Civil Engineering and Management 18(1): 5-13.

https://doi.org/10.3846/13923730.2011.619328

Seo, J.; Kim, Y.; Cho, J.; Jeong, S. 2013. Estimation of in situ dynamic modulus by using MEPDG dynamic modulus and FWD data at different temperatures, International Journal of Pavement Engineering 14(4): 343-353. https://doi.org/10.1080/10298436.2012.664274

Talvik, O.; Aavik, A. 2009. Use of FWD deflection basin parameters (SCI, BDI, BCI) for pavement condition assessment, The Baltic Journal of Road and Bridge Engineering 4(4): 196-202.

https://doi.org/10.3846/1822-427X.2009.4.196-202

Ullidtz, P. 1998. Modeling flexible pavement response and performance. Narayana Press, Gylling, Denmark.

Varma, S.; Kutay, M. E. 2016. Backcalculation of viscoelastic and nonlinear flexible pavement layer properties from falling weight deflections, International Journal of Pavement Engineering 17(5): 388-402. https://doi.org/10.1080/10298436.2014.993196

Varma, S.; Kutay, M. E.; Chatti, K. 2013a. Data requirements from falling weight deflectometer tests for accurate backcalculation of dynamic modulus master curve of asphalt pavements, in ASCE airfield \& highway pavement 2013. Los Angeles, California, 445-455. https://doi.org/10.1061/9780784413005.035

Varma, S.; Kutay, M. E.; Levenberg, E. 2013b. Viscoelastic genetic algorithm for inverse analysis of asphalt layer properties from falling weight deflections, Transportation Research Record: Journal of the Transportation Research Board 2369: 38-46. https://doi.org/10.3141/2369-05

Zhao, Y.; Bai, L.; Liu, H. 2014. Implementation of a triaxial dynamic modulus master curve in finite-element modeling of asphalt pavements, Journal of Materials in Civil Engineering 26(3): 491-498. https://doi.org/10.1061/(ASCE)MT.1943-5533.0000823

Žilionienè, D.; Luca, M. D.; Dell'Acqua, G. 2013. Evaluation of climatic factors based on the mechanistic-empirical pavement design guide, The Baltic Journal of Road and Bridge Engineering 8(3): 158-165. https://doi.org/10.3846/bjrbe.2013.20

Nader SOLATIFAR. PhD Candidate at the Department of Highway and Transportation Engineering, Faculty of Civil and Environmental Engineering, Tarbiat Modares University, Iran. MSc in Highway and Transportation Engineering (2011). Research interests: transportation infrastructures engineering and management, Pavement Management System (PMS), Non-Destructive Testing (NDT), asphalt pavements.

Amir KAVUSSI. Associate Professor at the Department of Highway and Transportation Engineering, Faculty of Civil and Environmental Engineering, Tarbiat Modares University, Iran. PhD in Pavement Engineering (1989). Research interests: asphalt mixtures and technology, pavement management and maintenance, pavement materials and pavement design.

Mojtaba ABBASGHORBANI. Head at Consultant Engineering Office, Technical and Soil Mechanics Laboratory, Ministry of Roads and Urban Development, Iran. PhD in Highway and Transportation Engineering (2016). Research interests: Pavement Management System (PMS), Non-Destructive Testing (NDT), performance tests.

Henrikas SIVILEVIČIUS. Prof. Dr Habil at the Department of Transport Technological Equipment, Faculty of Transport Engineering, Vilnius Gediminas Technical University, Lithuania. PhD in the Construction of Automobile Roads (1984). DrSc (2003) in Civil Engineering. Research interests: Hot Mix Asphalt (HMA), production quality and development of the quality control method, stochastic modelling and the application of statistical methods on the roads of flexible pavement construction, improvement in asphalt recycling technology, Multi-Criteria Decision Making (MCDM) in the transport system. 